\title{
Pachydermodactyly: A Benign Cutaneous Condition that May Be Misdiagnosed as a Joint Disorder
}

HOWARD CHU, MD, Department of Dermatology, Severance Hospital, Cutaneous Biology Research Institute, Yonsei University College of Medicine; JUNGSIK SONG, MD, Division of Rheumatology, Department of Internal Medicine, Yonsei University College of Medicine; DO YOUNG KIM, MD, Department of Dermatology, Severance Hospital, Cutaneous Biology Research Institute, Yonsei University College of Medicine, Seoul, Korea. Address correspondence to Dr. D.Y. Kim, Department of Dermatology and Cutaneous Biology Research Institute, Yonsei University College of Medicine, 50-1 Yonsei-ro, Seodaemun-gu, Seoul, Korea. E-mail: dykim@yuhs.ac. J Rheumatol 2016;43:1615-16; doi:10.3899/jrheum.160242

Pachydermodactyly is a rare, benign form of digital fibromatosis characterized by asymptomatic soft tissue swelling of the lateral aspects of the proximal interphalangeal (PIP) joints of the fingers. A 17-year-old male presented with a 4-year history of symmetrical thickening of PIP joints of all fingers, most prominent on second to fourth fingers (Figure 1). He had no symptoms such as pain or limitation of motion, had no family history, and denied the possibility of repetitive mechanical stress. To rule out the possibility of joint disorders, plain radiography was done, which showed only soft tissue thickening without any involvement of the joint or bone (Figure 2). A biopsy was then done, revealing only massive hyperkeratosis and thickening of dermis without deposition of mucin, indicating no involvement of pathological conditions. Based on these findings, a diagnosis of pachydermodactyly was made. Routine laboratory examinations including autoimmune panels were all negative or within normal range. Mild improvements were observed by applying salicylic acid and urea cream.

Pachydermodactyly predominantly affects adolescent males who usually have no family history, and may be associated with repetitive mechanical stimulations ${ }^{1}$, and can be confused with joint disorders or rheumatologic diseases ${ }^{2}$. There is no universally accepted treatment, while some have reported some effect with surgical resection or intralesional triamcinolone injections ${ }^{3}$. But because of its benign course and asymptomatic character, no aggressive treatment is required.

Pachydermodactyly is rare and may be easily misdiagnosed; the correct diagnosis is crucial in preventing the patient from getting unnecessary examinations and treatments.

\section{REFERENCES}

1. Seo SH, Sung HW. A case of pachydermodactyly. Ann Dermatol 2011;23:258-61.

2. Dallos T, Oppl B, Kovacs L, Zwerina J. Pachydermodactyly: a review. Curr Rheumatol Rep 2014;16:442.

3. Plana Pla A, Bassas Vila J, Toro Montecinos MA, Ferrandiz Foraster C. Pachydermodactyly successfully treated with triamcinolone injections. Actas Dermosifiliogr 2014;105:319-21.

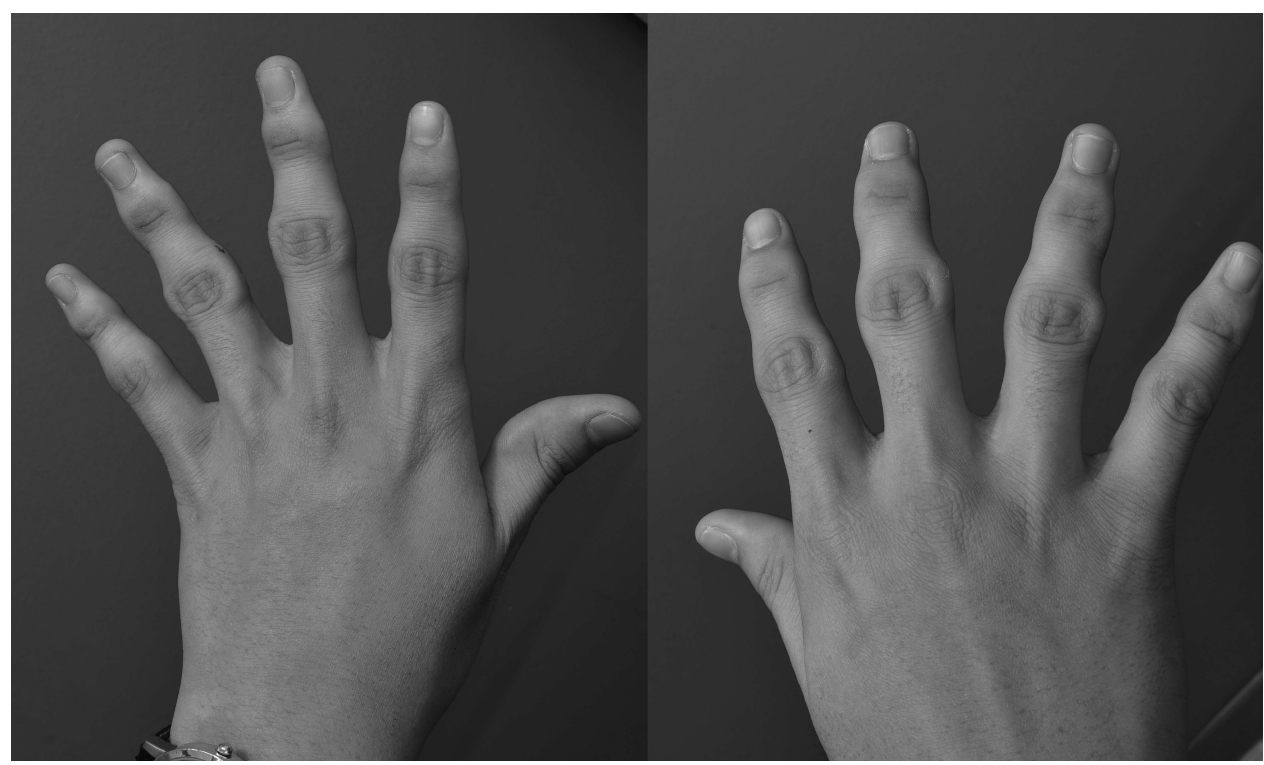

Figure 1. Thickening of the lateral aspects of the proximal interphalangeal joints of both hands. 


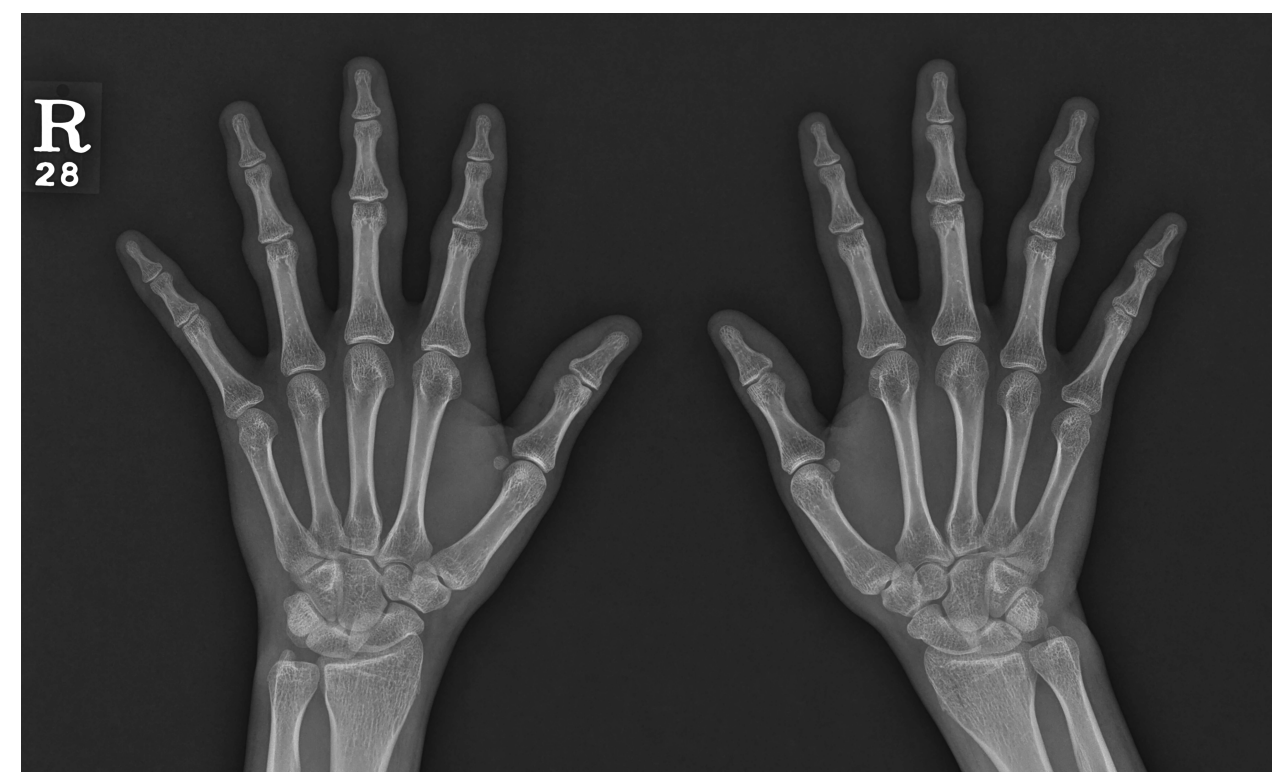

Figure 2. Plain radiography showed only soft tissue thickening without any involvement of the joint or bone. 